\title{
Fibulo-ulnar hypoplasia-renal anomalies syndrome
}

INSERM

\section{Source}

INSERM. (1999). Orphanet: an online rare disease and orphan drug data base. Fibuloulnar hypoplasia-renal anomalies syndrome. ORPHA:2256

Fibulo-ulnar hypoplasia-renal anomalies syndrome is characterized by fibuloulnar dysostosis with renal anomalies. It has been described in two sibs born to nonconsanguinous parents. The syndrome is lethal at birth (respiratory failure). Clinical manifestations include ear and facial anomalies (including micrognathia), symmetrical shortness of long bones, fibular agenesis and hypoplastic ulna, oligosyndactyly, congenital heart defects, and cystic or hypoplastic kidney. It is transmitted as an autosomal recessive trait. 